\title{
Arterial interventional chemotherapy and IMRT with concurrent chemotherapy for nasopharyngeal carcinoma with intracranial involvement
}

\author{
XINGLAI FEN, WEIFENG QIN，WUAN BAO，FENG JIANG，BIN LI，FUJUN HU and XIAOZHONG CHEN \\ Radiation Therapy Department of Oncology, Zhejiang Cancer Hospital, Hangzhou, Zhejiang 310022, P.R. China
}

Received November 18, 2012; Accepted January 30, 2013

DOI: $10.3892 / \mathrm{ol} .2013 .1407$

\begin{abstract}
The aim of this study was to ensure a high dose of intensity modulated radiation therapy (IMRT) was delivered to tumor tissue with a low dose to normal organs. Seldinger interventional techniques were used to inject chemotherapy drugs for nasopharyngeal carcinoma (NPC). IMRT was conducted 3 weeks after intervention. Primary tumor volume was reduced by $42.76 \%$ after 2 doses of interventional chemotherapy and intracranial tumor volume was reduced by $55.63 \%$. All patients presented grade II and above nasopharyngeal mucositis. In the 2 years following radiotherapy, overall survival (OS) was $83.3 \%$ and progression-free survival (PFS) was $75 \%$. In conclusion, T4 NPC patients with intracranial extension received induction chemotherapy followed by IMRT and concurrent chemotherapy, which proved to be efficacious and well tolerated.
\end{abstract}

\section{Introduction}

Nasopharyngeal carcinoma (NPC) is one of the most common malignant tumors, with its incidence rate ranking first among head and neck cancers. In China, more than $90 \%$ of NPC cases are pathological type III according to the World Health Organisation (WHO) criteria, and are sensitive to radiation. Therefore, for patients who are newly diagnosed and without metastasis, radiotherapy is the preferred treatment (1). In the last decade, the effect of NPC radiotherapy has been significantly improved. The local control rate of early NPC is $70-90 \%$, while that of T3-4 NPC is $50 \%$ (2).

Intensity modulated radiation therapy (IMRT) is a breakthrough in radiation oncology. It delivers a highly concentrated dose to the target area to kill tumor cells, while adjacent

Correspondence to: Dr Xiaozhong Chen, Radiation Therapy Department of Oncology, Zhejiang Cancer Hospital, 38 Guangji Road, Banshang Bridge, Hangzhou, Zhejiang 310022, P.R. China E-mail: xzh_chen@163.com

Key words: nasopharyngeal carcinoma, comprehensive treatment, interventional chemotherapy, intensity modulated radiation therapy healthy tissue is unaffected, which increases the gain ratio of radiotherapy. The local control rate of T1-3 patients is $>90 \%$, but that of T4 patients is only $\sim 85 \%$. In certain T4 NPC patients with intracranial extension, the space between the tumor and surrounding organs is small, so the radiation dose must be limited in order to protect the normal tissues and organs. This can result in local control failure and affect the survival rate (3).

In order to improve the local control rate and reduce distant metastasis, many clinical studies of treatment of locally advanced NPC with radical radiotherapy and chemotherapy have been performed. Since the results of intergroup 0099 trial were published $(4,5)$, the treatment strategy of NPC has been modified significantly and concurrent chemoradiotherapy has been used as the standard treatment of locally advanced NPC. Induction plus concurrent chemoradiotherapy is now standard in the treatment of NPC. A clinical phase II study has shown promising results with improved distant metastasis-free and overall survival; the choice of chemotherapy drugs, delivery methods and course number, however, needs further research. The European Society for Medical Oncology (ESMO) NPC clinical guidelines (6) suggest that while chemotherapy is not the standard treatment for NPC, it improved disease-free survival, suggesting that it may be used for the treatment of locally advanced NPC.

Arterial infusion chemotherapy has the features of high local drug concentration and a stronger effect of local tumor toxicity with low systemic side effects. It is used in the treatment of a variety of tumors.

The purpose of this study was to investigate the treatment of NPC patients with intracranial extension with arterial infusion chemotherapy. The aim was to reduce the volume of the primary tumor and expand the spatial distance between the tumor and vital organs. This will improve the dose distribution of IMRT and meet the target dose requirements while protecting the brain stem and nerve tissues. It is expected that by improving local treatment, overall survival (OS) time will also be improved. The aim was to find a combination providing optimal treatment for locally advanced NPC.

\section{Materials and methods}

General information. Twelve cases of NPC were selected between March and December 2009. All patients signed 
Table I. The intensity modulated radiation therapy (IMRT) target area.

\begin{tabular}{|c|c|}
\hline $\begin{array}{l}\text { Target area } \\
\text { name }\end{array}$ & Concept \\
\hline GTVnx & Including imaging visible primary tumor site \\
\hline GTVnd & $\begin{array}{l}\text { Including imaging visible and confirmable } \\
\text { metastatic cervical lymph nodes }\end{array}$ \\
\hline GTVrn & Retropharyngeal lymph node \\
\hline PGTVnx & $(G T V n x+$ GTVrn $)+$ extroverted 3-5 mm \\
\hline PTVnd & $\begin{array}{l}\text { Including (GTVnd }+ \text { around high-risk lymph } \\
\text { node) }+ \text { extroverted 3-5 } \mathrm{mm}\end{array}$ \\
\hline CTV1 & PGTVnx+ around high-risk lymph node \\
\hline PTV1 & CTV1 + extroverted 3-5 mm \\
\hline CTV2 & Including total neck lymph node drainage area \\
\hline PTV2 & $\mathrm{CTV} 2+$ extroverted $3-5 \mathrm{~mm}$ \\
\hline
\end{tabular}

A

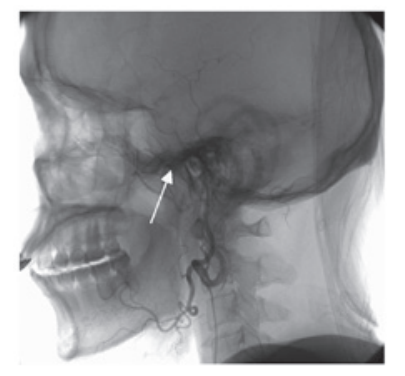

B

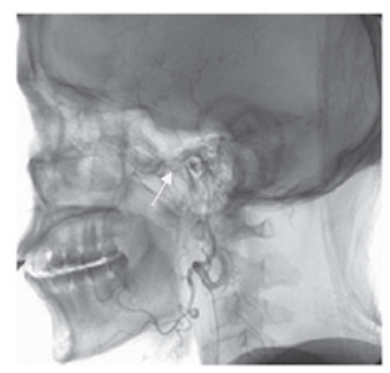

Figure 1. Changes in tumor blood supply. (A) Tumor blood vessel density in pars nasalis pharyngis is higher after first interventional therapy. (B) Tumor blood vessel density in pars nasalis pharyngis is reduced markedly after second interventional therapy.
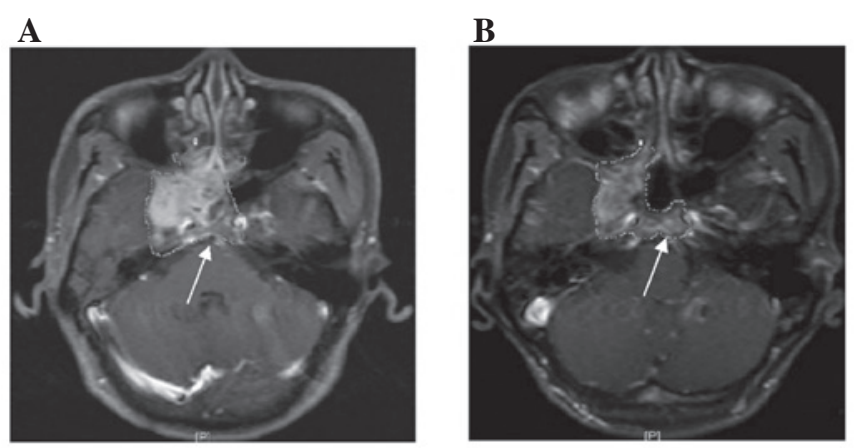

Figure 2. The tumor volume change. (A) The tumor volume is larger before interventional therapy. (B) The tumor volume is reduced after two interventional therapies.

informed consent before treatment. The study was approved by the Ethics Committee of Zhejiang Cancer Hospital, Hangzhou, China. Pathologically all types were WHO III, 11 cases were males and 1 case was female. Aged from 38 to 68 years, the average age was 52.7 years. The clinical stages of all cases demonstrated cavernous sinus and intracranial
Table II. Radiation dose.

\begin{tabular}{lccc}
\hline $\begin{array}{l}\text { Target area } \\
\text { name }\end{array}$ & $\begin{array}{c}\text { Single } \\
\text { dose }(\mathrm{Gy})\end{array}$ & $\begin{array}{c}\text { Total } \\
\text { dose }(\mathrm{Gy})\end{array}$ & Number \\
\hline PGTVnx & 2.3 & 69 & 30 \\
GTVnd & 2.2 & 66 & 30 \\
PTVnd & 2.1 & 63 & 30 \\
PTV1 & 2.0 & 60 & 30 \\
PTV2 & 1.8 & 54 & 30 \\
\hline
\end{tabular}

invasion indicating UICC 2002 staging T4N0-2M0IVa; the Karnofsky values were $\geq 80$. No patients had serious liver and kidney function, heart function and coagulation disorders or cerebral hemorrhage or infarction history.

Methods. Seldinger interventional techniques were used. Briefly, the patients were incubated percutaneous femoral artery puncture, catheterization of bilateral carotid artery, then angiography; next inserted into maxillary artery, ascending pharyngeal artery and branch of the target lesions. Chemotherapy drugs $\left(80 \mathrm{mg} / \mathrm{m}^{2}\right.$ cisplatin and $60 \mathrm{mg} / \mathrm{m}^{2}$ epirubicin) were injected the day after interventional therapy and $2,500 \mathrm{mg} / \mathrm{m}^{2} 5-\mathrm{FU}$ was administered using a chemotherapy electronic pump for $120 \mathrm{~h}$. There were 21 days per cycle. Two interventional treatments were conducted prior to radiotherapy. IMRT was conducted 3 weeks after intervention. During radiotherapy, two cycles of synchronous single-agent chemotherapy were conducted $\left(80 \mathrm{mg} / \mathrm{m}^{2}\right)$ (Tables I and II).

Observation methods and clinical evaluation. All patients gave routine blood samples and their liver and kidney function was tested every week before and during treatment. During treatment, tumor regression, general condition, mucous membrane and gastrointestinal reactions were checked and recorded. Nasopharyngoscopy and nasopharynx enhanced MR was performed before treatment, two weeks after the second intervention, at the end of radiotherapy, and 3 and 6 months after radiotherapy. Efficacy was evaluated according to the measurement standard of the WHO, as follows: Complete remission (CR): tumors disappear completely, the disappearance time is not less then 4 weeks; partial remission (PR): tumors shrink by more than $50 \%$, the remission time is 4 weeks or more; no change (NC): tumor shrinkage does not exceed $50 \%$ or increase does not exceed $25 \%$; tumor progression (PD): tumor increase $>25 \%$. Toxicity was evaluated according to the anticancer drug toxicity standard (CTC3.0).

\section{Results}

Changes in tumor blood flow. The 12 patients completed two interventional treatments. Digital subtraction angiography showed that the internal blood network of NPC reduced following interventional treatment at different degrees (Fig. 1).

Changes in tumor volume. The average tumor volume of the 12 patients was decreased from 45,730 to $26,174 \mathrm{~mm}^{3}$ after the 
Table III. Tumor volume changes and locations before and after interventional therapy.

\begin{tabular}{|c|c|c|c|c|c|c|c|c|c|c|}
\hline \multirow[t]{2}{*}{ Case } & \multicolumn{2}{|c|}{$\begin{array}{c}\text { Tumor } \\
\text { volume }\left(\mathrm{mm}^{2}\right)\end{array}$} & \multicolumn{2}{|c|}{$\begin{array}{c}\text { Intracranial } \\
\text { tumor volume }\left(\mathrm{mm}^{2}\right)\end{array}$} & \multicolumn{2}{|c|}{$\begin{array}{c}\text { Brain stem } \\
\text { distance }(\mathrm{mm})\end{array}$} & \multicolumn{2}{|c|}{$\begin{array}{c}\text { Optic nerve } \\
\text { distance }(\mathrm{mm})\end{array}$} & \multicolumn{2}{|c|}{$\begin{array}{l}\text { Optic chiasm } \\
\text { distance }(\mathrm{mm})\end{array}$} \\
\hline & Before & After & Before & After & Before & After & Before & After & Before & After \\
\hline 1 & 50760 & 33072 & 10025 & 4361 & 2.1 & 3.5 & 3.8 & 4.7 & 4.0 & 5.2 \\
\hline 2 & 67488 & 34920 & 16256 & 4782 & 1.2 & 4.0 & 3.2 & 4.5 & 3.8 & 6.5 \\
\hline 3 & 61344 & 48396 & 15991 & 4330 & 1.5 & 3.1 & 3.1 & 4.2 & 3.8 & 5.2 \\
\hline 4 & 35424 & 25200 & 6548 & 3356 & 2.6 & 3.6 & 5.5 & 5.5 & 4.2 & 5.0 \\
\hline 5 & 43332 & 24312 & 6452 & 4233 & 3.0 & 3.8 & 3.8 & 4.3 & 4.1 & 5.4 \\
\hline 6 & 32760 & 13872 & 5598 & 3945 & 3.0 & 3.7 & 4.8 & 5.0 & 4.8 & 5.3 \\
\hline 7 & 47160 & 24288 & 8256 & 3476 & 2.5 & 3.3 & 5.3 & 5.8 & 5.5 & 6.3 \\
\hline 8 & 69456 & 36132 & 13526 & 4621 & 1.2 & 2.8 & 3.3 & 4.8 & 4.4 & 6.0 \\
\hline 9 & 39960 & 6780 & 6058 & 2935 & 2.3 & 4.6 & 4.8 & 5.2 & 5.5 & 6.5 \\
\hline 10 & 23736 & 14964 & 7856 & 5046 & 3.2 & 3.5 & 5.2 & 5.6 & 4.8 & 5.2 \\
\hline 11 & 50220 & 30360 & 6880 & 3821 & 2.2 & 2.9 & 5.3 & 5.5 & 5.2 & 6.1 \\
\hline 12 & 27120 & 21792 & 7770 & 4438 & 2.8 & 3.2 & 4.7 & 6.1 & 5.1 & 6.9 \\
\hline Average & 45730 & 26174 & 9268 & 4112 & 2.3 & 3.5 & 4.4 & 5.1 & 4.6 & 5.8 \\
\hline
\end{tabular}
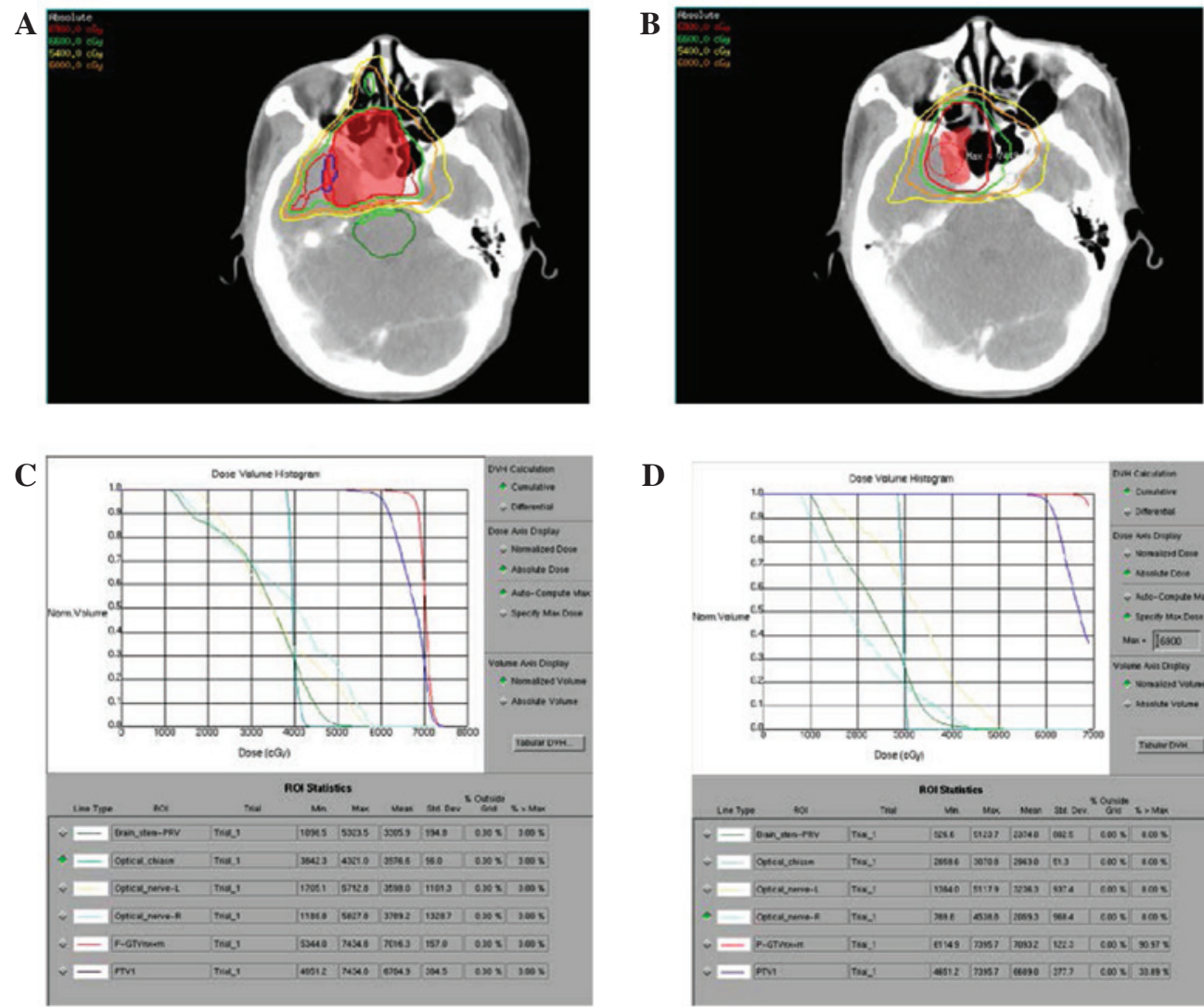

D

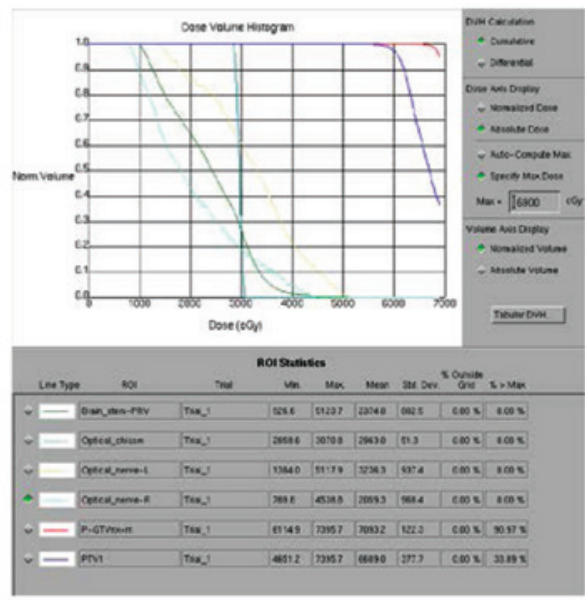

Figure 3. The intensity modulated radiation therapy (IMRT) change before and after interventional therapy. Isodose curve change of IMRT planning target volume before (A) and after (B) interventional therapy. Organ DVH change of IMRT planning target volume and organs at risk before (A) and after (B) interventional therapy. DVH, dose volume histogram.

second interventional chemotherapy, the average reduction was $42.76 \%$; the tumor intracranial total volume was reduced from 9,268 to $4,112 \mathrm{~mm}^{3}$, the average reduction was $55.63 \%$. The distance between the tumor and the brain stem, optic nerve and optic chiasm were expanded to $3.5,5.1$ and $5.8 \mathrm{~mm}$ from $2.3,4.4$ and $4.6 \mathrm{~mm}$, respectively (Fig. 2 and Table III). In order to meet the IMRT dose, $95 \%$ PTV must meet the dose of the target. The dose changes before and after intervention are shown in Table V. 


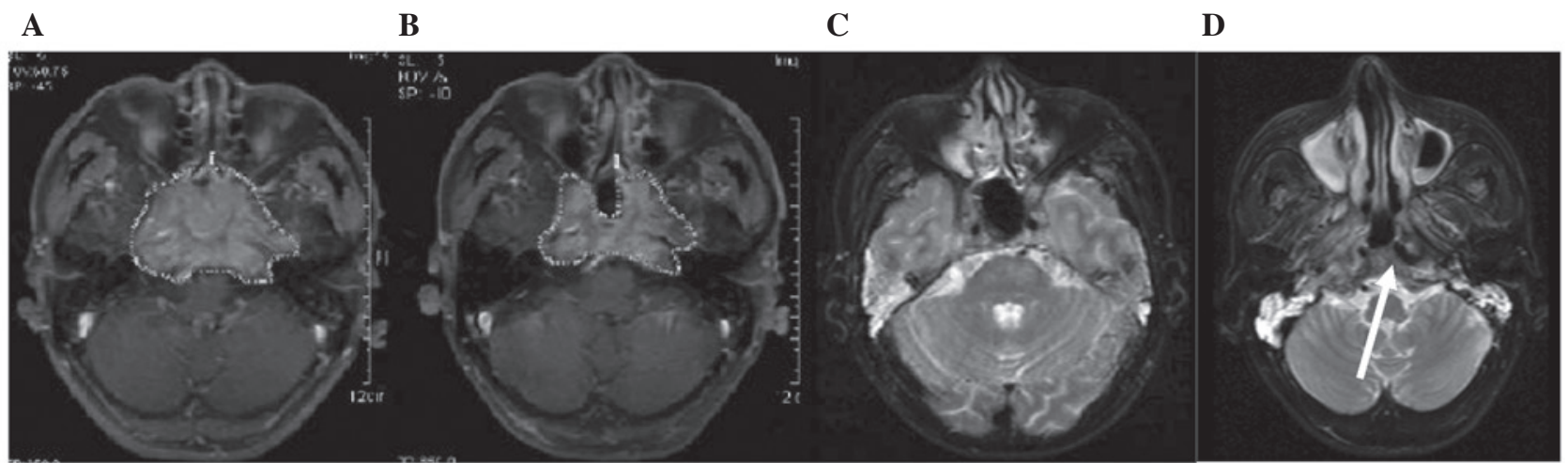

Figure 4. The follow-up outcome. (A) MR before therapy. (B) MR after two interventional chemotherapy treatments. (C) CR imaging after radiotherapy. (D) A deep ulcer appeared after 3 months of therapy.

Table IV. Side effects during interventional chemotherapy.

\begin{tabular}{|c|c|c|c|c|c|}
\hline \multirow[b]{2}{*}{ Side effect } & \multirow{2}{*}{$\begin{array}{l}\text { No. of } \\
\text { cases }\end{array}$} & \multicolumn{4}{|c|}{ WHO toxicity grading } \\
\hline & & I & II & III & IV \\
\hline Leucocyte decline & 6 & 1 & 3 & 2 & 0 \\
\hline Hemoglobin decline & 1 & 1 & 0 & 0 & 0 \\
\hline Platelet decline & 4 & 3 & 1 & 0 & 0 \\
\hline $\begin{array}{l}\text { Millet straw } \\
\text { transaminase rise }\end{array}$ & 3 & 3 & 0 & 0 & 0 \\
\hline Estomatitis & 2 & 1 & 0 & 0 & 0 \\
\hline Nausea & 8 & 5 & 2 & 1 & 0 \\
\hline Vomiting & 5 & 3 & 2 & 0 & 0 \\
\hline Diarrhea & 1 & 1 & 0 & 0 & 0 \\
\hline
\end{tabular}

Table V. Dose change of organs at risk before and after interventional therapy.

\begin{tabular}{lccc}
\hline $\begin{array}{l}\text { Target area } \\
\text { name }\end{array}$ & $\begin{array}{c}\text { Before } \\
\text { chemotherapy } \\
\text { MDL (Gy) }\end{array}$ & $\begin{array}{c}\text { Interventional } \\
\text { chemotherapy } \\
\text { MDL (Gy) }\end{array}$ & $\begin{array}{c}\text { Drop ratio } \\
(\%)\end{array}$ \\
\hline Brain stem & 66.2 & 56.1 & 15.26 \\
Optic chiasm & 60.3 & 53.6 & 11.11 \\
Optic nerve & 46.5 & 40.2 & 13.55 \\
Temporal lobe & 72.6 & 66.1 & 8.95 \\
\hline
\end{tabular}

MDL, maximum dose level.

Evaluation of tumors. At the end of radiotherapy the tumor situation was as follows: $6 \mathrm{CR}$ cases, 5 PR cases and $1 \mathrm{PD}$ case (distant metastasis appeared during radiotherapy, so treatment was changed to local palliative irradiation and systemic chemotherapy).

Follow-up. Three months after radiotherapy, the patients were followed up and 7 cases of CR, 3 cases of PR, 1 case
Table VI. Side effects with intensity modulated radiation therapy (IMRT) concurrent chemotherapy.

\begin{tabular}{|c|c|c|c|c|c|}
\hline \multirow[b]{2}{*}{ Side effect } & \multirow{2}{*}{$\begin{array}{l}\text { No. of } \\
\text { cases }\end{array}$} & \multicolumn{4}{|c|}{ WHO toxicity grading } \\
\hline & & I & II & III & IV \\
\hline Oral mucosa reaction & 12 & 2 & 8 & 2 & 0 \\
\hline $\begin{array}{l}\text { Nasal pharyngeal mucosa } \\
\text { reaction }\end{array}$ & 12 & 0 & 4 & 7 & 1 \\
\hline Skin reaction & 12 & 8 & 3 & 1 & 0 \\
\hline
\end{tabular}

of PD and 1 case of CR were found. One patient succumbed to nasopharyngeal ulcer hemorrhage. The nasopharynx and intracranial have a large tumor volume, tumor regression after interventional chemotherapy, nasopharyngeal mucosa reached grade IV at the end of radiotherapy and the local secondary infection failed to control, the ulcers invaded neck blood vessels and caused hemorrhage causing mortality (Fig. 4). The patients were followed up 2 years later. The OS and progression-free survival (PFS) rates were 83.3 and $75 \%$, respectively. One patient succumbed to nasopharyngeal ulcer hemorrhage, one succumbed to distant metastasis to multiple organs, and one patient recurred. However, there was no spinal cord, brain tissue or cranial nerve damage in any of the cases.

\section{Discussion}

IMRT is a revolution in radiation oncology technology, which has significantly improved treatment for NPC compared with conventional radiotherapy, although it still has a higher risk for T4 patients (7), particularly for T4 NPC patients with intracranial extension, whose tumor and vital organs (brain stem, optic nerve, optic chiasm and temporal lobe) are closely connected. Limiting the radiation dose protects the normal tissues and organs but may result in an insufficient dose to treat the tumor and lead to local control failure. Conversely, if the dose is too high it may lead to serious brain, spinal cord and neurological complications in the surrounding healthy organs (8). An insufficient dose to the tumor or excessive dose to normal tissue is a major obstacle for radiotherapy 
doctors. Induction radiotherapy plus concurrent chemotherapy has been shown to improve OS and local control rates of NPC (9-12). Interventional chemotherapy has become one of the treatments of a variety of tumors with the development of interventional techniques. Drugs injected directly into the tumor nutrient vessels with interventional chemotherapy increase the local concentration several times more than drugs injected systemically (13). Selective arterial chemotherapy can destroy a large number of cancer cells in a short period, which not only shrinks the tumor volume, reduces the hypoxic cells and improves the sensitivity of radiotherapy, but also expands the space between the tumor and other organs to implement IMRT radiotherapy.

This study showed that the primary tumor volume was reduced by $42.76 \%$ following two doses of interventional chemotherapy, and the intracranial tumor volume was reduced by $55.63 \%$. The distance from the brain stem, optic nerve and optic chiasm were increased by $1.2,0.7$ and $1.2 \mathrm{~mm}$, respectively. This resulted in a smaller GTVnx target. By ensuring the sufficient therapeutic dose to the tumor, the dosage in the brain stem, optic chiasm, optic nerve and temporal lobe were decreased by $15.26,11.11,13.55$ and $8.95 \%$.

The patients tolerated treatment well and had no serious grade IV adverse reactions to stop treatment. Compared to another study on conventional PF (DDP + 5-Fu) systemic induction chemotherapy (14), the patients did not have hematological toxicity, gastrointestinal tract, liver or kidney damage. At the end of radiotherapy, there were 6 cases of tumor CR $(50 \%)$ and 11 cases of CR plus PR (91.6\%). Two years after radiotherapy, OS was $83.3 \%$ and PFS was $75 \%$. After interventional chemotherapy, all patients presented grade II and above nasopharyngeal mucositis, 7 cases of grade III $(58.3 \%)$ and 1 case of grade IV $(8.3 \%)$. One patient succumbed to nasopharyngeal ulcer hemorrhage, tumor shrinkage in nasopharynx and intracranial after interventional chemotherapy was evidient, and nasopharyngeal mucosa appeared grade IV at the end of radiotherapy. Local secondary infection failed to control, the ulcers invaded neck blood vessels and caused hemorrhage and mortality.

According to research, T4 NPC patients with intracranial extension were given induction chemotherapy followed by IMRT plus concurrent chemotherapy with good success. This treatment method controlled tumors and protected the surrounding tissues and organs, which is a good choice for locally advanced T4 NPC patients. The OS and PFS were acceptable according to the 2-year follow-up. However, to help reduce the distant metastasis and local recurrence, long-term observation is required.

\section{References}

1. Qiu C, Yang N, Tian G, et al: Weight loss during radiotherapy for nasopharyngeal carcinoma: a prospective study from northern China. Nutr Cancer 63: 873-879, 2011

2. Yi JL, Gao L, Huang XD, et al: Nasopharyngeal cancinoma treated by radical radiotherapy alone: Ten-year experience of a single institution. Int J Radial Oncol Biol Phys 65: 161-168, 2006.

3. Lu T, Zhao C, Wu SX, et al: Retrospective analysis of 934 primary nasopharyngeal cancinoma (NPC) patients treated with conventional external-beam radiotherapy alone. Zhonghua Zhong Liu Za Zhi 60 (suppl): 508-509, 2004 (In Chinese).

4. Al-Sarraf M, Le Blanc M, Giri PG, et al: Chemoradiotherapy versus radiotherapy in patients with advanced nasopharyngeal cancer. Phase III randomized intergroup study 0099. J Clin Oncol 16: 1310-1317, 1998.

5. Al-Sarraf M, Le Blanc M, Giri PG, et al: Superiority of five year survival with chemo-radiotherapy (CT-RT) vs. radiotherapy in patients (Pts) with locally advanced nasopharyngeal cancer (NPC). Intergroup (0099) (SWOG 8892, RTOG 8817, ECOG 2388) phase III study: final report. Proc Am Soc Clin Oncol 20: 227a (abstract 905), 2001

6. Chan ATC and Felip E: Nasopharyngeal cancer: ESMO clinical recommendations for diagnosis, treatment and follow-up. Ann Oncol 20 (Suppl 4): 123-125, 2009.

7. Kam MK, Teo PM, Chau RM, et al: Treatment of nasopharyngeal cancinoma with intensity-modulated radiotherapy: the Hong Kong experience. Int J Radiat Oncol Biol Phys 60: 1440-1450, 2004.

8. Ngan RK, Yiu HH, Cheng HK, et al: Central nervous system metastasis from nasopharyngeal carcinoma: a report of two patients and a review of the literature. Cancer 94: 398-405, 2002.

9. Baujat B, Audry H, Bourhis J, et al: Chemotherapy in locally advanced nasopharyngeal carcinoma: an individual patient data meta-analysis of eight randomized trials and 1753 patients. Int J Radiat Oncol Biol Phys 64: 47-56, 2006.

10. Airoldi M, Gabriele AM, Gazaro M, et al: Induction chemotherapy with cispltin and epirubicin followed by radiotherapy and concurrent cisplatin in locally advanced nasopharyngeal carcinoma observed in a non-endemic population. Radiother Oncol 92: 105-110, 2009.

11. Palazzi M, Orlandi E, Bossi P, et al: Futher improvement in outcomes of nasopharyngeal carcinoma with optimized radiotherapy and induction plus concomitant chemotherapy: an update of the Milan experience. Int J Radiat Oncol Biol Phys 74: 774-780, 2009.

12. Hui EP, Ma BB, Leung SF, et al: Randomized phase II trial of concurrent cisplatin-radiotherapy with or without neoadjuvant docetaxel and cisplatin in advanced nasopharyngeal carcinoma. J Clin Oncol 27: 242-249, 2009.

13. Meng ZW, He EH, Meng ZL, et al: Timing changes of apoptosis and proliferating cells nuclear antigen after intra-arteiral infusion chemotherapy for nasopharyngeal carcinoma. Lin Chuang Er Bi Yan Hou Ke Za Zhi 14: 35-37, 2000 (In Chinese).

14. Hu F, Chen X, Jiang F, et al: Phase II trial of neoadjuvant chemotherapy plus concomitant chemotherapy and intensity modulated radiotherapy with adjuvant chemotherapy for locally advanced nasopharyngeal carcinoma. Zhejiang Med J 36: 836-839, 2010 (In Chinese). 